\title{
AS METAMORFOSES DA TERCEIRIZAÇÃO NA AMÉRICA LATINA: uma abordagem interdisciplinar sobre os conceitos, a partir de distintas realidades empíricas
}

\author{
Graça Druck* \\ Victoria Basualdo** \\ Alisson Droppa **
}

INTRODUÇÃO

O presente dossiê reúne um conjunto de artigos sobre o tema da terceirização, abordando uma discussão conceitual, das diferentes modalidades, das formas de regulação e das metodologias quantitativas e qualitativas, cuja problematização tem como referência pesquisas empíricas em diferentes setores e áreas do conhecimento. São análises que atualizam conceitos, diversidade de formas operativas, impactos nas condições de trabalho e na ação coletiva, mudanças nos marcos regulatórios, na última década; dialogando com a produção acadêmica latino-americana, especialmente nos países como Brasil, Argentina e Chile (Biavaschi; Droppa, 2021).

\footnotetext{
* Universidade Federal da Bahia. Faculdade de Filosofia e Ciências Humanas.

Estrada de São Lázaro, 197 - Federação. Cep: 40210-909. Salvador - Bahia - Brasil. druckg@gmail.com.

https://orcid.org/0000-0003-0363-6883

** Investigadora Independiente del CONICET y del Área de Economía y Tecnología de FLACSO.

Tucumán 1966, Ciudad de Buenos Aires. C1050AAN. Argentina.basuvic@yahoo.com.ar

https://orcid.org/0000-0003-4150-9797

*** Instituto Federal Riograndense.

Rua Mendes Sá, 800. Bom Sucesso. Cep: 13083-970. Gravataí - Rio Grande do Sul.

Universidade Estadual de Campinas.

Cidade Universitária Zeferino Vaz. Barão Geraldo. Campinas - São Paulo - Brasil. alissondroppa@gmail.com https://orcid.org/0000-0001-6568-9871
} 
mesmo tempo, essas reformas das políticas públicas têm ocorrido num contexto de fortes transformações científico-tecnológicas a nível internacional e regional, consolidando profundas mudanças nas formas de organização do trabalho, nas formas de produção e de relações de trabalho, tanto no setor público como no privado, em todas as atividades econômicas, abarcando a indústria, os serviços e a área rural.

Nesta medida, os estudos ora apresentados buscam revisitar e problematizar conceitos utilizados pelas pesquisas sobre terceirização, indicando as controvérsias, as lacunas, os argumentos que sustentaram decisões judiciais a partir de novos marcos regulatórios, buscando atualizar os conceitos e as diferentes formas de terceirização, numa perspectiva interdisciplinar, contemplando os campos da sociologia, economia, antropologia, história e do direito. Considera-se que este componente interdisciplinar é um elemento fundamental que articula os vários artigos e é essa a principal riqueza desse dossiê, que permite explorar esta problemática multifacetada e complexa a partir de diversas perspectivas e em conexão com outros processos fundamentais para as transformações das relações laborais. Trata-se de um esforço que tem como norte não apenas o debate acadêmico, mas que possa servir como referência nas formas de aferição do fenômeno e nas decisões judiciais.

Essa discussão conceitual, embora seja సิ o fio condutor do dossiê, é apresentada em sua సิ articulação com as diferentes realidades invesigadas, com análises de indicadores econômicos, sociais e jurídicos, tratando das metodologias quali e quanti dos estudos e apontando as insuficiências e necessidades de novas abordagens do fenômeno, a partir das particularidades em cada sociedade. Essa é uma das originalidades no tratamento da temática, além do diálogo interdisciplinar.

São nove artigos, que reúnem autores/as da Argentina, Brasil e Chile, vinculados/as a diversas instituições acadêmicas sendo cinco estrangeiros e doze brasileiros, das áreas de
Economia, Sociologia, Direito, Antropologia, História e Educação. Todos estudiosos da terceirização, com uma trajetória de pesquisas empíricas em diversos setores (metalúrgica, siderurgia, químico e petroquímico, call centers, telecomunicações, bancários, plataforma digitais, serviço público, dentre outros), que neste dossiê, se somam num esforço comum de debater e contribuir para as formulações conceituais, em diferentes níveis de abstração, de acordo com as singularidades de cada país objeto de análise. O diálogo entre esses especialistas de diferentes países, campos disciplinares e perspectivas se deu no marco de iniciativas de articulação acadêmica em distintos espaços, que incluíram a formação da Rede Interdisciplinar de Terceirização Laboral, criada no Seminário Internacional na FLACSO Argentina em 2018, além de outros espaços importantes como o GT CLACSO "Reformas Trabalhistas na América Latina: Abordagens e Diálogo", que iniciou suas atividades em 2020, bem como da participação de alguns dos autores numa mesa sobre terceirização no Encontro Nacional da ABET (Associação Brasileira de Estudos do Trabalho), realizado em Salvador/Bahia, em 2019.

Partindo de uma trajetória de estudos sobre o caso argentino, o artigo das pesquisadoras Victoria Basualdo CONICET- FLACSO e María Alejandra Esponda - UNAJ/FLACSO sintetiza um conjunto de contribuições para uma conceituação do fenômeno da terceirização laboral, construída a partir da análise do caso argentino em diálogo com formulações internacionais e publicações anteriores. Ao mesmo tempo, faz uma revisão de algumas das principais abordagens metodológicas desenvolvidas nos últimos anos na Argentina, que têm conseguido enfrentar as dificuldades de acesso à informação sobre o fenômeno e sua abrangência. O artigo articula contribuições coletivas e individuais que têm permitido análises quantitativas e qualitativas dos vários tipos de terceirização na Argentina, incluindo atividades e diversos segmentos do setor privado e do 
setor público, sublinhando a importância do cruzamento de contribuições de várias disciplinas, a confluência nos processos de trabalho coletivo e a articulação com protagonistas e sujeitos dessa história, cujas experiências são fundamentais para dar conta de uma dinâmica de enorme complexidade.

O artigo de Graça Druck e Isabela Fadul, ambas as professoras da UFBA, objetiva sistematizar e problematizar o conceito de terceirização nas pesquisas brasileiras, buscando estabelecer um diálogo entre diferentes áreas disciplinares de estudos, bem como indicar os diferentes níveis de abstração do conceito. Parte de uma definição mais ampla e estrutural do lugar da terceirização no capitalismo contemporâneo, marcado pela centralidade da precarização do trabalho e discute as diferentes formas de terceirização reveladas pelos estudos empíricos, para a partir deles, apresentar alguns conceitos operacionais, especialmente no campo jurídico. Além da problematização conceitual, apresentam uma proposta de criação de uma metodologia qualitativa para a construção de indicadores que permita mensurar a terceirização, tomando como "dados brutos”, os resultados de pesquisas empíricas realizadas no país.

O artigo de Magda Barros Biavaschi, Alisson Droppa e Marilane Oliveira Teixeira, todos pesquisadores da UNICAMP, fundamentado em pesquisas realizadas no âmbito do CESIT/Unicamp, traz à discussão a necessidade de se adotar um conceito amplo para a terceirização que a abarque em seus aspectos internos e externos, expressos e burlados, bem como discorre sobre a importância de buscar construir uma metodologia que permita melhor e mais amplamente medir essa forma de contratar. Para tanto, aborda algumas das formas de aferição, sugerindo a combinação de iniciativas para mapeá-la. Discute, também, os impactos da terceirização aprovada pela reforma trabalhista brasileira, sem limites para quaisquer atividades, ampliando as dificuldades para sua mensuração, trazendo maiores desafios na busca da cons- trução dessa metodologia. ${ }^{1} \mathrm{E}$, a partir do exame de um conjunto de instrumentos coletivos dos anos 2016 e 2019, analisa como a terceirização foi sendo tratada por esses instrumentos, sugerindo, inclusive, que a terceirização irrestrita e sua ampliação no contrato temporário foram absorvidas nessas negociações.

Sávio Cavalcante da UNICAMP e Paula Marcelino da USP defendem que, como já haviam afirmado em artigo publicado em 2012, "a terceirização é todo processo de contratação de trabalhadores por empresa interposta, cujo objetivo último é a redução de custos com a força de trabalho e/ou a externalização dos conflitos trabalhistas". (Marcelino; Cavalcanti, 2012, p. 331-346). O artigo afirma a validade dessa definição à luz dos acontecimentos, no Brasil, posteriores àquela publicação, quais sejam: processos julgados pelo Supremo Tribunal Federal (STF) e as leis que liberaram a terceirização de maneira irrestrita, promulgadas em 2017 (leis n.13.429 e n.13.467). Segundo os autores, aquela definição permanece válida e operacionalizável, demonstrada por meio de análise de textos produzidos e publicados em imprensa comercial, sindical e independente e documentos do STF além da sistematização de pesquisas realizadas no último período. Explicitam neste artigo o fundamento teórico que não estava exposto no texto revisitado, constituído por dois eixos: a relação do fenômeno da terceirização com a teoria do valor marxista, que salienta a subsunção da criação de valores de uso ao processo geral da valorização do capital; e a importância da estrutura jurídico-política para entender a conjuntura ampla e os fenômenos sociais em específico.

O texto de Andrea Del Bono e María Noel Bulloni, ambas pesquisadoras do CITRA/ CONICET-UMET, afirma que desde a década de oitenta do século passado, uma das características mais manifestas do capitalismo é a terceirização da força de trabalho, e que na atua-

1 Sobre a reforma trabalhista brasileira e seus impactos nos Mundos do Trabalho, consultar: Krein; Teixeira, 2021; Krein, José Dari et al, 2021; Krein; Oliveira, Filgueiras, 2019. 
lidade, as possibilidades abertas pelos avanços tecnológicos e os processos de digitalização da economia têm aprofundado o alcance e o impacto das formas "clássicas" de terceirização e subcontratação laboral. O artigo analisa algumas interpretações do campo dos estudos do trabalho na região e reflete - a partir de uma leitura crítica dos processos de flexibilização produtiva e do trabalho - sobre a atual abrangência do fenômeno da terceirização. A análise das autoras trata da problematização dos efeitos da terceirização do trabalho para argumentar, com base em diversos estudos nos países da região, que se trata de uma estratégia de flexibilização que, em sua complexidade, traz formas de trabalho com menores níveis de proteção e estabilidade, e que em termos gerais, impacta de maneira negativa a dialética capital-trabalho. E, por fim, articulam essas análises com o fenômeno das novas dinâmicas socioeconômicas e do trabalho que surgem no marco do processo de digitalização da economia e expansão do trabalho de plataformas, enquadrado pela generalização das práticas de terceirização que acarretam a desproteção dos trabalhadores e das trabalhadoras.

O objetivo do artigo de Renata Dutra UNB e Vitor Filgueiras - UFBA é definir e relacionar os conceitos de terceirização e uberização, interpretando os dois fenômenos como estratégias de gestão da força de trabalho que buscam reduzir os limites à exploração do tra$\overrightarrow{\mathcal{N}}$ balho. O ponto central da discussão é perceber సิ que, assim como não ocorria na terceirização, tampouco na uberização há delegação ou externalização das atividades, que persistem sob o o controle das empresas, as quais continuam $\rightarrow$ subordinando os trabalhadores aos seus coÆ̛ mandos. De acordo com os autores, há, no ar-

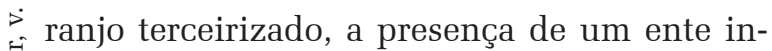
terposto, singularidade que o define, enquanto que na uberização, a contratação dos trabalhadores pelas empresas imputa a eles o status de autônomos, usando a tecnologia digital para gerir o trabalho de forma arbitrária, instável e imprevisível para quem trabalha. O artigo ob- serva ainda que as empresas vêm utilizando simultaneamente a terceirização e a uberização como forma de gestão, embora os autores considerem que são fenômenos distintos, por acentuarem a mercadorização do trabalho.

O artigo de Sebastián Pérez Sepúlveda - IRISSO, sustenta que a definição de empresa é um prisma fundamental a partir do qual se analisa o complexo fenômeno da terceirização. O artigo aborda essa problemática a partir do caso chileno, onde a definição de empresa ocupa um lugar central na legislação trabalhista, com consequências sociais e políticas decisivas para o mundo do trabalho. O autor analisa o processo de consolidação e regulação da terceirização no país e, em seguida, aborda de forma mais precisa a definição de uma empresa e seu escopo à luz da realidade contemporânea da terceirização no Chile. A este respeito, defende que os diversos processos associados à terceirização, bem como a sua própria realidade material - especialmente a amplitude da subcontratação da atividade principal - tencionam a definição jurídica da empresa, colocando à prova constantemente seus limites e contornos, tanto nos termos da arena do direito do trabalho, bem como na experiência cotidiana de trabalho e da luta sindical.

Sayonara Grillo e Rodrigo Carelli, ambos professores da UFRJ, examinam as respostas às demandas que envolvem a terceirização no cenário pós reforma trabalhista. Perguntam se os julgamentos do STF - que rechaçou as alegações de inconstitucionalidade da legislação, declarou a licitude da terceirização e superou a distinção entre atividades empresariais acessórias e finalísticas - colocaram um ponto final no debate judicial. Utilizando os procedimentos metodológicos de levantamento jurisprudencial e análise documental, com mapeamento de ações julgadas no último biênio, examinam os argumentos nos litígios, investigando acerca da modificação em padrões decisórios. A pesquisa conclui que as controvérsias sobre fraudes em terceirização permanecem em disputa na Justiça do Trabalho, submetida ao controle do 
Supremo, que apresenta posições contraditórias em relação a esse aspecto. Outro achado da pesquisa é que o requisito da "capacidade econômica” está ausente do debate. A emergência de questões fáticas, as fricções entre a Justiça do Trabalho e o Supremo e os argumentos sobre responsabilidade empresarial apontam para a persistência de disputas na arena judiciária mesmo após o novo marco regulatório.

$\mathrm{O}$ artigo de Marcia Leite, UNICAMP, visa retomar a discussão dos estudos que evidenciaram os efeitos devastadores da terceirização sobre os trabalhadores e seus órgãos de representação, a aprovação de legislações que favorecerem cada vez mais a sua adoção pelas empresas e as estratégias dos sindicatos para enfrentar a nova realidade. A autora parte do contexto internacional em que a terceirização se difunde e as formas que ela se reveste, indicando a complexidade do fenômeno e as dificuldades para sua definição. Em sua análise sobre a evolução da terceirização na prática das empresas, da mudança da legislação e da ação sindical frente às transformações no caso brasileiro, contextualiza dois momentos (anos 1990 e no período 2003/2017); mostrando as possibilidades e os limites da luta sindical nos dois períodos; bem como situa, em suas considerações finais, a ofensiva contra o trabalho e os trabalhadores, após a derrota política de 2016, agravada pela situação criada pela pandemia no país.

Em suma, o conjunto de abordagens incluídas neste dossiê - baseadas em valiosas trajetórias e processos de acumulação coletiva de pesquisas, reunindo estudiosos do "mundo do trabalho", vinculados a instituições acadêmicas diversas e comprometidos com as lutas sociais -, permite identificar tanto a relevância da terceirização quanto sua estreita relação com outros fenômenos fundamentais como as mudanças tecnológicas, as reformas trabalhistas e os limites do direito do trabalho e das instituições que o operam, as novas formas de organização do trabalho, as dificuldades da organização sindical, no contexto do capitalismo flexível, globalizado e financeirizado.
Este esforço coletivo que busca enfrentar os enormes desafios que envolvem a conceituação, mensuração e análise empírica da terceirização, numa perspectiva interdisciplinar permite, no contexto de uma série de debates, manifestar algumas certezas significativas. Em primeiro lugar, destaca-se a relevância da análise das conexões destes fenômenos que atravessam as fronteiras nacionais, ressaltando a importância do trabalho colaborativo de pesquisadores e equipes de diferentes países. Em segundo lugar, evidencia a extensão muito ampla da terceirização em um grande número de atividades econômicas, assumindo várias formas e modalidades. Em terceiro lugar, há unanimidade quanto aos impactos negativos sobre os trabalhadores, em termos de níveis salariais, condições de trabalho, estabilidade, treinamento, formação e as dificuldades de organização sindical.

Por fim, os textos evidenciam a necessária distinção entre áreas e níveis de análise que conduzem a distintas categorias e conceituações, em particular distinguindo o campo jurídico e o da pesquisa em ciências sociais, que podem ter um diálogo muito fecundo, desde que se compreenda as especificidades de suas abordagens e escopo. Ao mesmo tempo, destaca-se a coincidência das múltiplas conexões e transformações da terceirização em estreita relação tanto com as mudanças normativas como com os processos tecnológicos, que geram dinâmicas e suportes antes impossíveis.

Numa fase de enorme transformação das relações de trabalho no quadro das brutais mudanças econômicas e sociais ocorridas no contexto da pandemia, que aguçou e aprofundou várias estratégias empresariais para subtrair direitos adquiridos, fruto de décadas de lutas e organização, esperamos que este esforço conjunto seja útil e convidamos a todos a lerem o dossiê.

Recebido para publicação em 26/09/2020. Aceito em 26/10/2021. 


\section{REFERÊNCIAS}

BASUALDO, Victoria; MORALES, Diego. (Org.) La tercerización laboral: Orígenes, impacto y claves para su análisis en América Latina. Buenos Aires: Siglo Veintiuno Editores, 2014.

BASUALDO, Victoria et. al. Tercerización y derechos laborales en la Argentina actual. Bernal: Editorial de la Universidad Nacional de Quilmes, 2015.

BIAVASCHI, Magda Barros; DROPPA, Alisson. (Org.) Terceirização e as reformas trabalhistas na América Latina. Buenos Aires, CLACSO, 2021.

BORGES, Angela; FRANCO, Tania. Mudanças de gestão: para além dos muros da fábrica. In: FRANCO, Tânia (Org.). Trabalho, riscos ambientais e meio ambiente: rumo ao desenvolvimento sustentável. Salvador: EDUFBA, p. 63116, 1997.

DRUCK, Graça. Terceirização: (des)fordizando a fábrica - Um estudo do complexo petroquímico da Bahia. São Paulo: Boitempo, 1999.

DRUCK, Graça; FRANCO, Tania. A degradação do trabalho e os riscos industriais no contexto da globalização, reestruturacão produtiva e das políticas neoliberais. In: FRANCO, T.(org.) - Trabalho, Riscos Industriais e Meio Ambiente: Rumo ao Desenvolvimento Sustentável? p.1532. EDUFBA. Salvador, 1997.
KREIN, José Dari; TEIXEIRA, Marilane Oliveira. (Org.) $O$ Trabalho Pós-Reforma Trabalhista. Campinas - SP: CESITUnicamp e REMIR Trabalho, 2021.

KREIN, José Dari et al. Org. As negociações coletivas pós reforma trabalhista de 2017. 1. ed. Campinas - SP: CESITUnicamp e REMIR Trabalho, 2021.

KREIN, José Dari; OLIVEIRA, Roberto. Veras; FILGUEIRAS, Victor. Org. Reforma trabalhista no Brasil: promessas e realidade. Campinas: Curt Nimuendajú, 2019.

KREIN, José Dari. Tendências recentes nas relações de emprego no Brasil - 1990/2005. Tese (Doutorado em Economia) - IE/UNICAMP, 2007.

MARCELINO, Paula; CAVALCANTE, Sávio. Por uma definição de terceirização. Cadernos $C R H$, v. 25, p. 331$346,2012$.

MARTINS, Heloísa; RAMALHO, José Ricardo. Terceirização - Diversidade e Negociação no Mundo do Trabalho. São Paulo: Hucitec, 1994.

Graça Druck - Doutora em C. Sociais pela UNICAMP. Professora titular do Programa de Pós-graduação em C. Sociais da Faculdade de Filosofia e C. Humanas e do Programa de Serviço Social da Universidade Federal da Bahia. Pesquisadora do CRH/UFBa. Bolsista Produtividade do CNPq. Membro da REMIR. Integra e lidera o Grupo de Pesquisa Trabalho, Trabalhadores e Reprodução social do Diretório do CNPq. Desenvolve pesquisas ná área de sociologia do trabalho. Publicações recentes: co-organizadora com Jair Batista da Silva do livro Trabalho, Precarização e Resistências, Edufba (2019); co-autora com Luiz Filgueiras do livro O Brasil nas Trevas - (2013 - 2020): do golpe neoliberal ao neofascismo, Boitempo (2020).

Victoria Basualdo - Doutora em Historia pela Columbia University (NY), Professora da Maestría em Economía Política en la Universidade Facultad Latinoamericana de Ciencias Sociales, Coordenadora do Programa "Estudios del trabajo, movimento sindical y organización industrial" na Área de Economia e Tecnologia da FLACSO, desenvolvendo pesquisas no campo dos estudos do trabalho e do movimento sindical desde a segunda metade do século XX até a atualidade, na Argentina e na América Latina. Seu livro mais recente é: Big Business and Dictatorships in Latin America A Transnational History of Profits and Repression, Palgrave Macmillan, 2021, coordenado junto com Hartmut Berghoff y Marcelo Bucheli; $O$ Caso da Acindar Villa Constitución e o ciclo de transformações repressivas, produtivas e trabalhistas entre ditadura e democracia”, en Revista Continentes, Ano 8, n.16, jan./jun., 2020. ISSN: 2317-8825; Procesos de conflictividad laboral en el marco de la pandemia del COVID-19 en Argentina (marzo-mayo 2020), en Dossier "trabalho e instituições em mudança" en REI - Revista Estudos Institucionais, Universidade Federal de Rio de Janeiro, Brasil, v. 6, n. 3 (2020), p. 1086-1134. ISSN: 2447-5467

Alisson Droppa - Doutor em História Social do Trabalho. Trabalha com temas relacionados à terceirização dos serviços na América Latina, especialmente sobre as ações encaminhadas ao poder judiciário trabalhista. Publicou, entre outros textos, o livro: Direitos trabalhistas: legislação, justiça do trabalho e trabalhadores no Rio Grande do Sul (1958- 1964). 1. ed. Curitiba: Editora CRV. 